IGCS20_1142

\section{LAPAROSCOPIC APPROACH TO COMPREHENSIVE SURGICAL STAGING FOR CLINICAL STAGE I ENDOMETRIAL CANCER: AN INSTITUTIONAL REVIEW OF OPERATIVE OUTCOMES, COSTS AND ITS CLINICAL IMPLICATIONS}

G Facun*, R Sicam, D Benavides. Philippine General Hospital, Philippines

10.1136/ijgc-2020-IGCS.136

Objectives The absence of local oncologic results utilizing laparoscopic surgery for early stage endometrial cancer prevents its adoption as procedure of choice in the Philippines. The purpose of this study was to determine the clinical profile, operative outcomes and costs of undergoing laparoscopic surgery for clinical stage I endometrial cancer.

Methodology Data from 28 patients who underwent TLHBSO, PFC, LND for presumed stage I endometrial cancer were collected retrospectively from May 2017 to May 2019 in a tertiary institution.

Results Mean age of the patients was 46.7 (range, 25 to 71). Risk factors included obesity (53.5\%), nulliparity (46.4\%), diabetes mellitus (14.3\%), primary infertility (14.3\%), PCOS, (7.1\%) and dyslipidemia (3.6\%). None of the cases were converted to laparotomy, one necessitated mini-laparotomy to deliver the uterine specimen. Median length of operations was 236 minutes and 281 minutes depending on whether paraaortic lymphadenectomy was included. Complications include blood transfusion (3), vaginal vault dehiscence (1) and lymphocyst formation (1). Mean hospital stay was 7 days. Blood loss was minimal $(217.3 \pm 171.4 \mathrm{~mL})$. Two out of the 28 cases have stage III disease intra-operatively. Median follow up was 13.5 months. Sixteen subjects $(57 \%)$ had no evidence of disease on follow up while $2(7 \%)$ already died of disease. The presence of LVSI and tumor size $\geq 2 \mathrm{~cm}$ were factors identified for progression. Average hospital cost was $\$ 1,137.15$ (range, \$336.47 to \$2,386.98).

Conclusion Laparoscopic surgery is a safe and viable surgical option for carefully selected clinical stage 1 endometrial cancer patients.

\section{IGCS20 1143}

\section{NON-EPITHELIAL OVARIAN TUMORS: A SINGLE INSTITUTE RETROSPECTIVE STUDY}

${ }^{1}$ I de Sá* ${ }^{2}$ S Raposo, ${ }^{2} \mathrm{R}$ Sousa, ${ }^{2} \mathrm{~L}$ Sá. ${ }^{1}$ Centro Hospitalar de Trás-os-Montes e Alto Douro, Portugal; ${ }^{2}$ Instituto Português Oncologia Francisco Gentil, Portugal

\subsection{6/ijgc-2020-IGCS.137}

Introduction Non-epithelial ovarian tumors (NEOT) account for $10 \%$ of ovarian cancers. They occur in all age groups and include diverse tumors of germ cell origin, sex cord-stromal cell origin, as well as extremely rare types of ovarian cancer. The etiology and molecular origins of each sub-group remain poorly understood. Our aim is to determine the clinical, epidemiologic and histological features of the NEOT.

Methods A retrospective coorte study involving 33 patients diagnosed with NEOT and treated at IPO-Coimbra between
2011-2015. Patients 'data were obtained from hospital records.

Results The average age was 56 years. $42.4 \%$ of the patients were pre menopausal. We diagnosed 11 germ cell tumors ( 9 mature cystic teratomas, 1 mature teratoma and 1 immature teratoma), 21 sex cord-stromal tumors (16 ovarian fibromas/ thecomas, 3 adult granulosa cell tumors, 1 juvenile granulosa cell tumor and 1 Sertoli-Leydig cell tumor) and 1 small cell carcinoma hypercalcaemic type tumor. All patients had surgery as a primary treatment; in $18.2 \%$ of the cases was performed a conservative surgery. Only $9.1 \%$ of patients were diagnosed in a stage > IA (FIGO). 2 patients were subjected to adjuvant chemotherapy (Sertoli-Leydig cell tumor and immature teratoma). After a mean follow up of 2.2 years, we reported 3 cases of relapse. 3 patients died between 2011-2015, but only one due the disease. The overall survival at 5 years was $97 \%$.

Conclusions Our study reveals that the overall prognosis of NEOT is good. Relapse cases were mainly related to FIGO stage and more rare histologic type of tumor.

\section{IGCS20 1144}

\section{TARGET THERAPY IN HEAVILY PRETREATED WOMEN AFFECTED BY DIFFERENT CANCERS: A PRELIMINARY SINGLE CENTER EXPERIENCE AFTER THE INTRODUCTION OF COMPREHENSIVE GENOMIC PROFILING IN CLINICAL PRACTICE}

${ }^{1} S$ Cappuccio*, 'MV Carbone, ${ }^{1} \mathrm{~A}$ Pietragalla, ${ }^{1} \mathrm{AM}$ Cozzolino, ${ }^{2} \mathrm{~V}$ Ghizzoni, ${ }^{1} \mathrm{G}$ Scambia. ${ }^{1}$ Fondazione Policlinico A. Gemelli, IRCCS, Italy; ${ }^{2}$ Università Cattolica del Sacro Cuore, Italy

\subsection{6/ijgc-2020-IGCS.138}

Introduction Cancer treatment is evolving towards precision medicine. When traditional chemotherapy is not effective anymore in heavily pretreated patients, tumour profiling can be an helpful tool able to match genomic data to available target therapies.

Methods Patients treated at our Gynaecologic Oncology Unit from $09 / 2018$ to $06 / 2020$ with no other available standard options were proposed for the FOUNDATIONONE ${ }^{\circledR} \mathrm{CDx}$ genomic profiling. Clinical data were collected. In case of targetable alterations, patients were treated with the suggested molecular-driven treatments, when possible. Follow-up is still ongoing.

Results We collected specimens and clinical data of 67 patients. The majority were ovarian tumors $(44 / 67 ; 65.7 \%)$; $18 / 67$ patients $(26.8 \%)$ had no mutation detected, one $(1.5 \%)$ had not enough cancer cells in the specimen and 10/67 $(14.9 \%)$ tests are ongoing. Of the 38 patients with a viable targeted therapy, 16 (28.9\%) were treated with a FOUNDATIONONE ${ }^{\circledR}$ CDx-guided targeted therapy, 5 of those with PARP-inhibitors within approved indications; one $(2.6 \%)$ is waiting to start. The remaining $(21 / 38 ; 55.3 \%)$ died before starting or decided for no therapy for poor performance status (tables 1-2).

Conclusions In the era of precision medicine, integration of molecular biology and targeted therapy is an effective option especially for patients with heavily treated cancers. Large randomized trials are needed to draw relevant conclusions about the patient clinical outcomes improvement and correct 